\title{
Retraction note: Precipitation behavior of B2-ordered aluminide
}

\author{
Chang-Suk Han
}

\author{
Retraction note: Met. Mater. Int., Vol. 12, No. 6, pp. 467-475 (2006) \\ DOI: 10.1007/BF03027746
}

This Retraction Note expands on the Retraction Note previously published in Metals and Materials International, November 2014, Volume 20, Issue 6, p 1169 (http://dx.doi.org/10.1007/s12540-014-6024-4)

The editorial board of Metals and Materials International has decided to retract this article for reasons of plagiarism and redundant (duplicate) publication.

Several paragraphs and figures in the manuscript have been used without indication that those paragraphs and figures had been published previously. The most original source papers are:

Precipitation of $\alpha$-Cr in B2-ordered $\mathrm{NiAl}$

W. H. Tian, C. S. Han and M. Nemoto, Intermetallics 7 (1999) 59-67

Dislocation loops and phase decompositions of B2-FeAl(Co) compound in Fe-Al-Co Ternary system

W. H. Tian and M. Nemoto, Intermetalics 10 (2002) 641-646

Precipitation behavior of nitrides in L10-ordered TiAl

W. H. Tian and M. Nemoto, Intermetallics 13 (2005) 1030-1037

The online version of the original article can be found under doi: 10.1007/BF03027746

\section{Chang-Suk Han*}

Dept. of Defense Science and Technology, Hoseo University

165, Sechul-Ri, Baebang-myeon, Asan-si, Chungnam 336-795, Korea

e-mail: hancs@office.hoseo.ac.kr

(CKIM and Springer 